\title{
Synthesis of a new zeolite, intergrowth of Erionite and Chabazite
}

\author{
Sreeprasanth Pulinthanathu Sree ${ }^{* a}$, Elke Verheyen ${ }^{\mathrm{a}, \mathrm{b}}$, Michiel De Prins ${ }^{\mathrm{a}}$, Tom Van der Donck ${ }^{\mathrm{c}}$, \\ Leen van Tendeloo ${ }^{b}$, Frank Schuetze ${ }^{d}$, Johan A. Martens ${ }^{* a}$
}

\author{
a. Centre for Surface Chemistry and Catalysis, University of Leuven, Leuven, 300o, Belgium \\ b. Umicore, Olen, 2250, Belgium \\ c. Department of materials Engineering, University of Leuven, Leuven, 300o, Belgium \\ d. Umicore AG \& Co. KG, Hanau, 63456, Germany
}

\begin{abstract}
A new zeolite, COK-24 which is an intergrowth of Erionite (ERI), and Chabazite (CHA) was successfully synthesized for the first time. This was realized via a mixed gel approach. The formation of an intergrowth was confirmed via XRD combined with advanced electron microscopy. The new zeolite intergrowth outperformed its individual counterparts in $\mathrm{NH}_{3}$-SCR reaction.
\end{abstract}

For more than 6o years, zeolites play key role in industrial processes such as catalysis, gas adsorption and separation, ion exchange and environmental protection. Zeolite synthesis is controlled by many parameters, often resulting in physical mixtures or intergrowths rather than phase pure zeolites. In many cases, intergrowth materials show special catalytic, sorptive or molecular separation properties compared to their phase pure end members or physical mixtures. This can be seen for the ERI/OFF in catalytic dewaxing [1], for MFI/MEL intergrowth in the methanol to hydrocarbon conversion [2] and the enhanced stability of AEI/CHA for dimethyl ether to olefins conversion [3]. Different types of zeolite intergrowths are epitaxial and polytypical intergrowths [4]. As intergrowth, polytypism is a more common phenomenon in zeolite crystallization. It can be pictured as a stacking of different structurally uniform domains in each individual crystal, without any mismatch of bonds. The different types of domains can be structurally related, for example when they represent a different periodicity. This most often occurs as an alternative stacking of a common sheet, such as in FAU/EMT $[5,6]$ or MFI/MEL [7]. Sometimes they have substantially different structures such as in MAZ/MOR [8] and the *BEA, a family of distorted zeolite materials [9]. The stacking pattern can then vary from a strict alternation to domain arrangements with no periodicity at all. Specifically for the ABC-6 zeolite family of materials, polytypism as an intergrowth is well known. Materials belonging to the ABC- 6 family are for example chabazite, offretite, erionite, gmelinite, sodalite and levynite. The structure of zeolite materials in the ABC-6 family can be represented as a stacking of layers containing planar six-rings (6Rs). The 6Rs in one layer can be connected to the next layers of 6Rs in different ways. The three different locations of the 6 Rs in a layer can be given as A, B or C.

The 6Rs in the different layers can be connected parallel to each other (position A) or by a shift (position B and C), resulting in different frameworks belonging to the ABC-6 family. For example, offretite can be represented by three connecting layers with a stacking sequence of $A A B$, whereas the erionite contains 6 unique layers with a sequence of AABAAC. A stacking fault between one of these layers, where the stacking sequence is slightly altered at some places, results in intergrowths of different framework types, such as the ERI/OFF intergrowth.

Whereas polytypism arises when individual sheets in a layered material are stacked in different sequences, epitaxy on the other hand, involves the oriented overgrowth of a zeolite crystal by a compositional or structurally different zeolite phase, Examples are the structural overgrowth of zeolite X on zeolite A [10], zeolite P on zeolite A [11], or FAU/EMT overgrowth materials [12]. Within the ABC-6 material family, also known as the chabazite group, an OFF/LEV overgrowth exists [13]. Examples of a compositional overgrowth can be found in the combination of ZSM-5 or ZSM-11 and silicalite-1 [14].The outer shell is a pure $\mathrm{SiO}_{2}$ layer that has crystallized on the aluminosilicate ZSM-5 zeolite. Also the opposite is possible where the pure $\mathrm{SiO}_{2}$ inner part is combined with an aluminum-containing isostructural outer shell [15].

Today, the majority of known zeolites are small-pore zeolites, defined by pore openings limited by 8 atoms in tetrahedral coordination. Small-pore zeolites have been frequently used in gas separation, adsorption and in detergents $[16,17]$. Recently, new applications are also arising for 
a

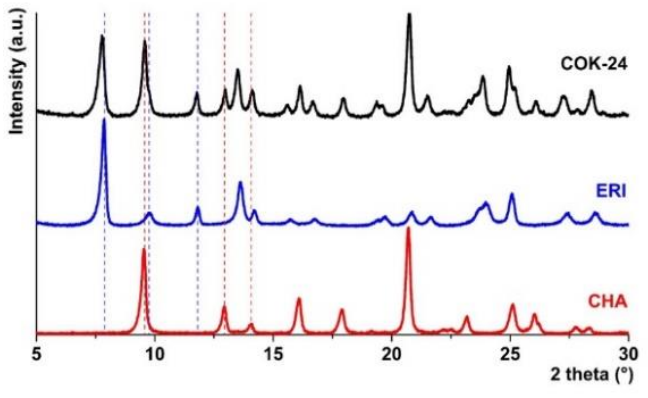

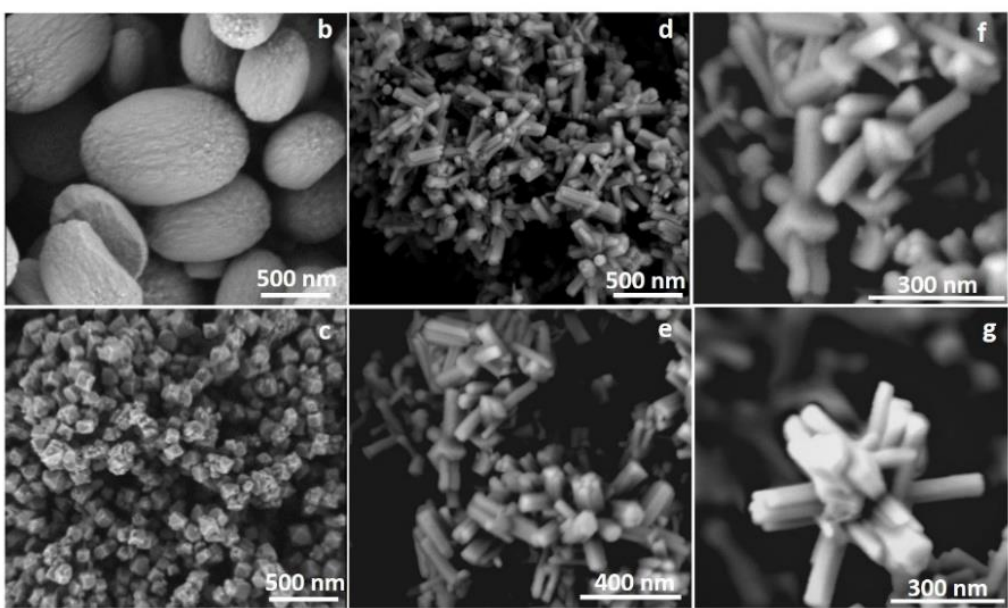

Figure 1. (a) XRD patterns of CHA, ERI and COK-24. HRSEM of (b) ERI, (c) CHA and (d-g) COK-24.

small-pore zeolites comprising a transition metal, such as selective catalytic reduction of NOx (SCR) for abatement of the pollution from car exhaust or methanol-to-olefins (MTO) reactions $[17,18]$. Due to their constricting pore dimensions, small-pore zeolites loaded with copper are suggested to have a higher resistance to zeolite dealumination upon severe hydrothermal ageing compared to their medium- or large-pore counterparts [19]. This is beneficial for the upcoming SCR-Catalyzed Diesel Particulate Filter (sDPF) applications, where the SCR catalysts is combined with a diesel particulate filter (DPF) and regeneration temperatures can reach up to $900{ }^{\circ} \mathrm{C}[20,21]$.

The dual-template synthesis is frequently employed for the synthesis of intergrowths, using both organic structure directing agents necessary for the synthesis of the phasepure end members, in one synthesis gel. Examples are the AEI/CHA[22], AFX/CHA[23] and ZSM-22/ZSM-23 [24] intergrowths.

This manuscript describes the synthesis and characterization of a new zeolite intergrowth (COK-24) through mixed gel synthesis and its superior performance in $\mathrm{NH}_{3}-$ SCR catalysis compared to the phase-pure zeolites, synthesized separately.

COK-24 zeolite is obtained via a mixed gel approach, where two separate synthesis gel mixtures are combined before hydrothermal synthesis. More specific, the synthesis gels of one-pot $\mathrm{Cu}-\mathrm{CHA}$ and ERI are combined. The molar composition of both gels is well known for the synthesis of CHA and ERI, respectively. If synthesized individually, one aluminosilicate gel yields a one-pot $\mathrm{Cu}-\mathrm{CHA}$ and consists of a FAU zeolite, $\mathrm{Cu}$-TEPA and $\mathrm{NaOH}$. The second aluminosilicate solution is made from a silicon- and aluminum-source, TEAOH, hexamethoniumbromide and $\mathrm{KCl}$, which is a common recipe for the synthesis of ERI zeolite. The XRD patterns of both CHA and ERI zeolite are shown in Figure 1a. Both phases are well crystallized and phase pure. Combining both synthesis gels immediately before the hydrothermal synthesis results in a physical mixture of ERI and CHA. However, allowing the two synthesis gels to age separately for 2 days under static conditions, prior to mixing followed by hydrothermal synthesis, results in the formation of the COK-24 zeolite. The XRD pattern of the COK-24 zeolite in Figure 1a. clearly shows a combination of reflections ascribed to ERI as well as CHA zeolite.

SEM images of ERI, CHA and COK-24 are shown in Figure 1b-g. ERI crystals (Figure 1b) can be described as elongated spheres with an average length of around $850 \mathrm{~nm}$, while CHA zeolite (Figure 1c) has a cubic morphology and consists of cubes with sizes around $100 \mathrm{~nm}$. The crystal morphology of COK-24 (Figure 1d-g) is clearly not a physical mixture of ERI and CHA and can be best described as cubes with elongated rods growing out from or in to different facets of the cubes. This also indicates there are two different growth orientations.

By combining bright field (BF) TEM and selected area electron diffraction (SAED), it is possible to allocate the ERI and CHA in COK-24. In Figure 2, a BF TEM image of COK-24 shows a cluster of crystals containing elongated rods with a node in the middle. SAED patterns were obtained from four different parts of the cluster. The three elongated rods Figure $\mathbf{2}(\mathbf{a}, \mathbf{b}$ and $\mathbf{c})$ are identified as ERI zeolite. Each of the three crystals are aligned along the [10o] direction with the $c^{*}$-axis oriented along the longer dimension of the crystal. SAED also confirms that the node is CHA zeolite (d), aligned close to its [10o] direction. ERI and CHA crystal zones share a common c-axis orientation, confirming the presence of an intergrowth. This is the first time the ERI/CHA intergrowth has been achieved experimentally.

HRTEM image, shown in Figure 2 (e-f), further confirms that COK-24 zeolite is ERI/CHA intergrowth. The bottom part of the image shows the CHA phase (e) and the upper part shows the ERI structure (f), both confirmed by the Fourier transform. This confirms the orientation as shown by SAED, shown in the insets of corresponding parts.

Thermogravimetric analysis indicated that the organic structure directing agents are incorporated in the zeolites. 


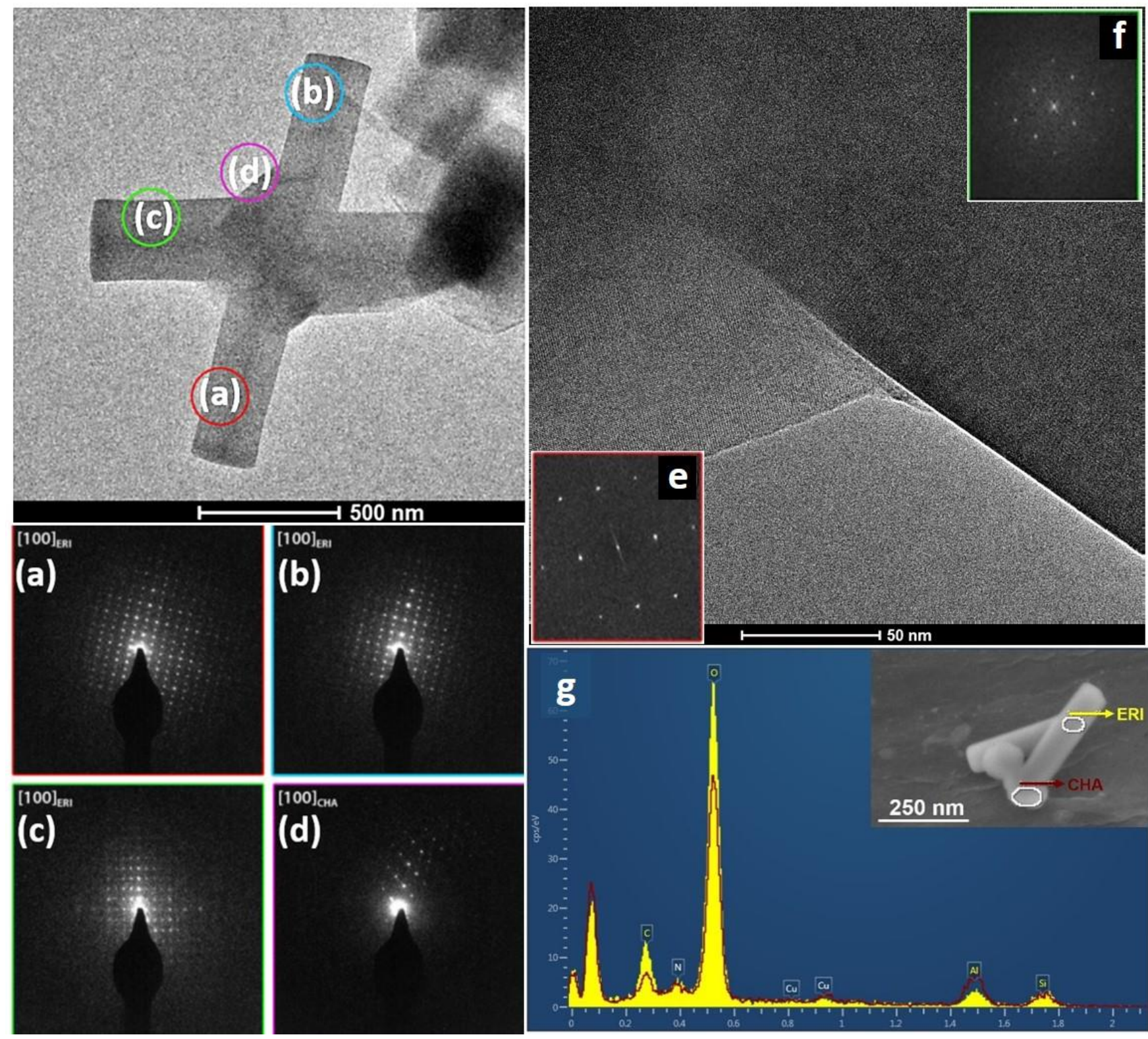

Figure 2. Bright field TEM (top left) and Selected area electron diffraction (bottom left) of selected parts of COK-24. HRTEM of COK-24 (top right) indicating (e) CHA phase at the lower part of the image and (f) ERI structure at the upper part and corresponding Fourier transforms in the insets. Low voltage accelerating EDS X-ray analysis $(g)$ on COK-24 presenting differences in template and Cu content at CHA and ERI parts shown in the inset.

The ERI, CHA and COK-24 contain respectively $2.5 \mathrm{wt} . \%$, $10.5 \mathrm{wt} . \%$ and $13 \mathrm{wt} . \%$ of organics in the final zeolite. Low voltage accelerating EDS analysis, Figure 2 (g), clearly showed that both the ERI and CHA phase in the ERI/CHA intergrowth (COK-24) contain organic template and is even able to differentiate the template in the respective zeolite phase. A template with a low carbon to nitrogen molar ratio $(\mathrm{C} / \mathrm{N})$ is $\mathrm{Cu}$-TEPA $(\mathrm{C} / \mathrm{N}$ equal to 1.6$)$. Both the tetraethylammonium and the hexamethonium have a higher $\mathrm{C} / \mathrm{N}$ ratio of, respectively, 8 and 6 . It can be seen in Figure $2(\mathrm{~g})$ that the ERI phase has a much higher $\mathrm{C} / \mathrm{N}$ compared to the CHA fraction. It is therefore more likely that the majority of the tetraethylammonium and hexamethonium are incorporated in the ERI phase and majority of Cu-TEPA in the CHA fraction.
Chemical analysis was performed on COK-24 intergrowth, pure CHA and ERI zeolite after calcination. COK24 zeolite has a SAR of 12.6. This is higher than that obtained for pure CHA (SAR 8.7) and lower than the ERI zeolite (SAR 15.7). Due to the introduction of $\mathrm{Cu}$ during the synthesis, a $2.2 \mathrm{wt} \% \mathrm{Cu}$ content in the COK-24 zeolite is obtained in the one-step synthesis procedure. Also CHA is a one-pot $\mathrm{Cu}$ zeolite, containing a high amount of $\mathrm{Cu}$ in the final zeolite reaching $6.5 \mathrm{wt} . \% \mathrm{Cu}$. Based on the total yield of the synthesis of COK-24 and CHA (2 g and $1.5 \mathrm{~g}$, respectively), the template amount ( $13 \%$ and $10.5 \%$, respectively) and $\mathrm{Cu}$ content in the calcined zeolite (2.2 and $6.5 \mathrm{wt} . \%$, respectively), it can be calculated that $0.038 \mathrm{~g}$ and $0.087 \mathrm{~g}$ of $\mathrm{Cu}$ is incorporated in the final COK-24 and CHA. For both zeolites, o.095 $\mathrm{g}$ of $\mathrm{Cu}$ is added to the synthesis, 

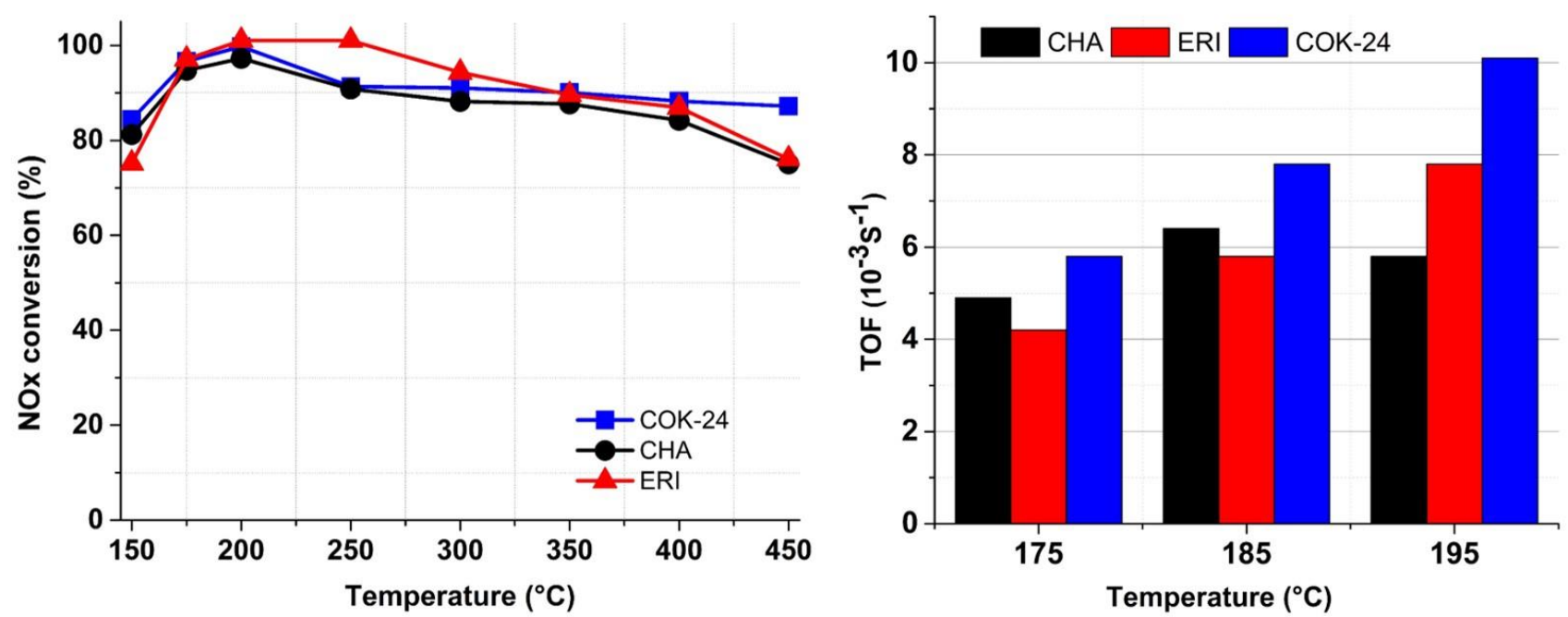

Figure 3. (left) NOx conversion (\%) of CHA, ERI and COK-24. (right) Turnover frequency (TOF) of CHA, ERI and COK-24 at temperatures of 175,185 and $195^{\circ} \mathrm{C}$.

resulting in a $\mathrm{Cu}$ incorporation of $40 \%$ and $92 \%$ for $\mathrm{COK}$ 24 and CHA, respectively. In case of pure one pot CHA zeolite, almost all $\mathrm{Cu}$ included in the synthesis is incorporated in the final zeolite, whereas the efficiency of $\mathrm{Cu}$ incorporation is lower in the ERI/CHA intergrowth, most likely due to the presence of the ERI zeolite. This was confirmed via Low voltage accelerating Energy Dispersive Xray Spectroscopy (EDS) analysis, Figure 2 (g) and Electron Energy Loss Spectroscopy (EELS) (Supplementary Information Fig $\left.\mathrm{S}_{1}-\mathrm{S}_{4}\right)$.

As $\mathrm{Cu}$ is already included during synthesis of the COK24, this zeolite is ideally suited as $\mathrm{NH}_{3}-\mathrm{SCR}$ catalyst. The phase pure ERI zeolite was loaded with $\mathrm{Cu}$ post synthesis so that it could be compared to the catalytic activity of the COK-24 intergrowth. This $\mathrm{Cu}$ loading on ERI was performed via a wet ion-exchange with copper acetate to obtain $2.7 \mathrm{wt}$ \% $\mathrm{Cu}$ in the zeolite.

Figure 3 a. shows the NOx conversion in function of temperature for CHA, ERI and COK-24. All catalysts show a high activity already at low temperatures. However, at $450^{\circ} \mathrm{C}, \mathrm{COK}-24$ distinguishes itself from CHA and ERI by maintaining this high activity, indicating superior selectivity toward the $\mathrm{NOx}$ to $\mathrm{N} 2$ reaction. The turnover frequency (TOF; mol NO converted / $\mathrm{mol} \mathrm{Cu}$ * $\mathrm{s}$ ) describes the intrinsic activity of $\mathrm{Cu}$ active sites in the $\mathrm{NH}_{3}-\mathrm{SCR}$ catalysts and is compared in Figure $3 \mathrm{~b}$. At each temperature, the COK24 outperforms the separately synthesized phase pure zeolites.

The hydrothermal stability of the COK-24 is clearly improved compared to the ERI and CHA phase pure samples. After a hydrothermal ageing at $750^{\circ} \mathrm{C}$ of the $\mathrm{Cu}$ loaded zeolites, only the COK-24 zeolite retains its structural integrity. This again emphasizes the superior performance of COK-24 for $\mathrm{NH}_{3}$-SCR applications. Compared to the CHA, the ERI/CHA is an improved one-pot $\mathrm{Cu}$-catalyst for $\mathrm{NH}_{3}-$ SCR in terms of both higher activity, selectivity and stability. A higher SAR and a lower Cu content contribute to this superior performance. This is most likely due to the presence of ERI phase in the ERI/CHA intergrowth.
The ERI/CHA zeolite is made by combining the two separate zeolite synthesis gels of ERI and $\mathrm{Cu}-\mathrm{CHA}$. Via this mixed gel approach, an intergrowth of ERI and CHA was obtained. Crucial for this approach is the separate ageing time of the two synthesis gels. Omitting this step resulted in a mere physical mixture of ERI and CHA or pure ERI. Small differences in molar gel composition are allowed for the synthesis of ERI/CHA intergrowth. Lowering the amount of ERI gel (aluminosilicate solution 2) to $80 \%$, resulting in molar oxide gel composition $\mathrm{SiO}_{2} / 0.026 \mathrm{Al}_{2} \mathrm{O}_{3}$ / $0.44 \mathrm{NaOH} / 0.034 \mathrm{KCl} /$ o.020 Cu-TEPA / o.30 TEAOH / $0.0466 \mathrm{RBr} / 31 \mathrm{H} 20$, allows to synthesize an ERI/CHA with a SAR ratio of 13.6 and a $\mathrm{CuO}$ content of $3.3 \mathrm{wt} . \%$. From $\mathrm{XRD}$ and SEM, it is obvious that also in the final ERI/CHA intergrowth, the ERI fraction is reduced. Further variations in the gel composition, i.e. keeping the amount of gels the same and altering the cations and slight variations in the template amount also resulted in the successful synthesis of ERI/CHA intergrowth with different ratios of individual components. No ERI/CHA was formed when the synthesis time or temperature were drastically reduced to 2 days or $95{ }^{\circ} \mathrm{C}$, respectively. Only after 4 days at $160{ }^{\circ} \mathrm{C}$, the ERI/CHA intergrowth is formed.

Experimental

COK-24 zeolite synthesis

The Cu-tetraethylenepentamine complex (Cu-TEPA) was synthesized by adding $37.9 \mathrm{~g}$ tetraethylenepentamine (o.2 mole, Sigma-Aldrich) to a solution consisting of $50 \mathrm{~g} \mathrm{CuSO}_{4} \cdot \mathrm{H}_{2} \mathrm{O}$ (o.2 mole, SigmaAldrich) and $200 \mathrm{~g}$ of $\mathrm{H}_{2} \mathrm{O}$ (1 M solution) at room temperature upon stirring. This solution continued stirring for $\mathbf{2} \mathrm{h}$ at room temperature.

$3 \mathrm{~g}$ of zeolite $\mathrm{Y}$ with SAR $=30$ (CBV-720, Zeolyst International) was suspended in $27 \mathrm{~mL}$ of a $1.2 \mathrm{M}$ solution of sodium hydroxide at room temperature. To this solution, $1.5 \mathrm{~mL}$ of a $1 \mathrm{M} \mathrm{Cu}$-TEPA solution was added. The final gel has the following molar ratios: $\mathrm{SiO}_{2} / 0.033 \mathrm{Al}_{2} \mathrm{O}_{3}$ / o.033 Cu-TEPA / o.70 NaOH / $34 \mathrm{H}_{2} \mathrm{O}$. This suspension was stirred for $15 \mathrm{~min}$ at room temperature and then kept static and heated at $95^{\circ} \mathrm{C}$ for $48 \mathrm{~h}$ in a closed polypropylene bottle (PP bottle) and is referred to as aluminosilicate solution 1.

Aluminosilicate solution 2 was prepared as follows: $0.28 \mathrm{~g}$ aluminum-tri-sec-butoxide (Fluka) was added upon stirring for $5 \mathrm{~min}$ at room temperature to $12.43 \mathrm{~g}$ tetraethylammonium hydroxide (35 wt.- 
$\%$, Sigma-Aldrich) in a $60 \mathrm{~mL}$ PP bottle. This mixture was stirred mechanically for 10 minutes. To this solution, $5.46 \mathrm{~g}$ Ludox AS-40 (SigmaAldrich) was added drop wise within 10 minutes at room temperature upon stirring and afterwards $1.65 \mathrm{~g}$ hexamethonium bromide (Acros) was added at once. Another $0.25 \mathrm{~g}$ of potassium chloride (LabChem) and $5.02 \mathrm{~g}$ of distilled water was added within $2 \mathrm{~min}$. The final gel has the following molar ratios: $\mathrm{SiO}_{2} / 0.015 \mathrm{Al}_{2} \mathrm{O}_{3} / 0.092 \mathrm{KCl} / 0.81 \mathrm{TEAOH}$ / $0.13 \mathrm{RBr} / 25 \mathrm{H}_{2} \mathrm{O}$, where $\mathrm{R}$ is the hexamethonium organic template. This solution remained stirring for $24 \mathrm{~h}$ in the closed PP bottle at room temperature and forms a liquid gel. This gel was aged for another 48 $\mathrm{h}$ at room temperature without stirring.

After the aging step, aluminosilicate solution 2 was added at once to aluminosilicate solution 1 at room temperature. The final gel has the following molar ratios: $\mathrm{SiO}_{2} / 0.025 \mathrm{Al}_{2} \mathrm{O}_{3} / 0.39 \mathrm{NaOH} / 0.041 \mathrm{KCl}$ / $0.018 \mathrm{Cu}$-TEPA / $0.36 \mathrm{TEAOH} / 0.0553 \mathrm{RBr} / 30 \mathrm{H}_{2} \mathrm{O}$, where $\mathrm{R}$ is the hexamethonium organic template. The resulting mixture was homogenized by vigorous stirring for 15 minutes and afterwards transferred to a stainless steel autoclave. This mixture was heated for $168 \mathrm{~h}$ at $160{ }^{\circ} \mathrm{C}$ under dynamic conditions under autogenous pressure. The solid product was recovered by filtration and washing with $500 \mathrm{~mL}$ deionized water, and was dried at $60{ }^{\circ} \mathrm{C}$ overnight. The yield of the synthesis was $2 \mathrm{~g}$. The zeolite was calcined at $750{ }^{\circ} \mathrm{C}$ for $8 \mathrm{~h}$ with a temperature ramp of $1^{\circ} \mathrm{C} / \mathrm{min}$.

\section{ASSOCIATED CONTENT}

(Supporting Information is available free of charge via the Internet at http://pubs.acs.org."

Experimental details ; synthesis , characterization ,catalysis. Dark Field STEM image and EEL spectrum.

\section{AUTHOR INFORMATION}

\author{
Corresponding Authors \\ Dr. Sreeprasanth Pulinthanathu Sree \\ * sree.psree@kuleuven.be \\ Prof. Johan Martens \\ * johan.martens@kuleuven.be
}

\section{Author Contributions}

The manuscript was written through contributions of all authors.

\section{ACKNOWLEDGMENT}

Authors acknowledge Dr. Adrian Sandu, Thermo Fisher Scientific (FEI) Eindhoven, Dr. James Sagar and Mr. James Holland, Oxford Instruments UK for their help in Low voltage accelerating EDS X-ray analysis. J. A. M. acknowledge the Flemish Government for long-term structural funding (Methusalem) for financial support.

\section{REFERENCES}

1. NY Chen, JL Schlenker, WE Garwood, GT Kokotailo, TMAOffretite: Relationship between structural and catalytic properties, J Catal, 1984, 86, 24-31

2. JM Thomas, GR Millward, Direct, real-space determination of intergrowths in ZSM-5/ZSM-11 catalysts, J Chem Soc Chem Commun, 1982, 1380-1383

3. D Zhao, Y Zhang, Z Li, Y Wang, J Yu, Synthesis of SAPO18/34 intergrowth zeolites and their enhanced stability for dimethyl ether to olefins, RSC Adv., 2017, 7, 939-946

4. CNR Rao, JM Thomas, Intergrowth structures: The chemistry of solid-solid interfaces, Acc Chem Res, 1985, 13, 113119

5. MW Anderson, KS Pachis, F Prébin, SW Carr, O Terasaki, T Ohsuna, V Alfredsson, Intergrowths of cubic and hexagonal polytypes of faujasitic zeolites, J Chem Soc Chem Commun, 1991, 1660-1664
6. MMJ Treacy, DEW Vaughan, KG Strohmaier, JM Newsam, Intergrowth Segregation in FAU-EMT Zeolite Materials, Proc R Soc Lond A - Math Phys Eng Sci , 1996, 452, 813-840

7. GR Millward, S Ramdas, JM Thomas, Evidence for semiregularly ordered sequences of mirror and inversion symmetry planes in ZSM-5/ZSM-11 shape-selective zeolitic catalysts, J Chem Soc Faraday Trans.2, 1983, 79, 1075-1082

8. ME Leonowicz and DEW Vaughan: Proposed synthetic zeolite ECR-1 structure gives a new zeolite framework topology, Nature, 1987, 329, 819-821

9. MMJ Treacy, JM Newsam, Two new three-dimensional twelve-ring zeolite frameworks of which zeolite beta is a disordered intergrowth, Nature, 1988, 332, 249-251

10. E de Vos Burchart, JC Jansen, H van Bekkum: Ordered overgrowth of zeolite X onto crystals of zeolite A, Zeolites, 1989, 9, 423-435

11. DW Breck, Zeolite Molecular Sieves: Structure, Chemistry and Use, John Wiley \& Sons, New York, 1974

12. AM Goossens, BH Wouters, PJ Grobet, V Buschmann, L Fiermans, JA Martens, Synthesis and Characterization of Epitaxial FAU-on-EMT Zeolite Overgrowth Materials, Eur J Inorg Chem, 2001, 1167-1181

13. WS Wise, RW Tschernich, The chemical compositions and origin of the zeolites offretite, erionite, and levyne, Am Mineral, 1976, 61, 853-863

14. LD Rollmann, ZSM-5 particle containing aluminum-free shells on its surface, 1976, U.S. Patent 4,148,713A

15. SJ Miller, Crystalline silicate particle having an aluminumcontaining outer shell, 1981, U.S. Patent 4394362A

16. W Vermeiren, JP Gilson, Impact of zeolites on the petroleum and petrochemical industry, Top. Catal., 2009, 52, 1131-1161

17. M Moliner, C Martínez, A Corma, Synthesis strategies for preparing useful small pore zeolites and zeotypes for gas separations and catalysis, Chem. Mater, 2014, 26, 246-258

18. U Olsbye, S Svelle, M Bjørgen, P Beato, TVW Janssens, F Joensen, S Bordiga, KP Lillerud, Conversion of methanol to hydrocarbons: how zeolite cavity and pore size controls product selectivity, Angew. Chem. Int. Ed., 2012, 51, 58105831

19. PG Blakeman, EM Burkholder, H Chen, JE Collier, JM Fedeyko, H Jobson, RR Rajaram, The role of pore size on the thermal stability of zeolite supported Cu SCR catalysts, Catalysis Today,2014, 231, 56-63

20. A Kawakami, T Mizutani, SAE Tech. Pap. 2012-o1-o8

21. T Ryu, NH Ahn, S Seo, J Cho, H Kim, D Jo, GT Park, PS Kim, CH Kim, EL Bruce, PA Wright, IS Namand, SB Hong, Fully copper-exchanged high-silica LTA zeolites as unrivaled hydrothermally stable $\mathrm{NH}_{3}$-SCR catalysts, Angew. Chem., Int. Ed., 2017, 56, 3256-326o.

22. D Zhao, Y Zhang, Z Li, Y Wang, J Yu, Synthesis of AEI/CHA intergrowth zeolites by dual templates and their catalytic performance for dimethyl ether to olefins, Chemical Engineering Journal,2017, 323, 295-303

23. Y Naraki, K Ariga, K Nakamura, K Okushita, T Sano, ZTS1 and ZTS-2: Novel intergrowth zeolites with AFX/CHA structure, Microporous and Mesoporous Materials, 2017, 254, 160-169

24. B Wang, Z Tian,P Li, L Wang, Y Xu, W Qu, H Ma, Z Xu, L Lin Synthesis of ZSM-23/ZSM-22 intergrowth zeolite with a novel dual-template strategy, Materials Research Bulletin, 2009, 44, 2258-2261 


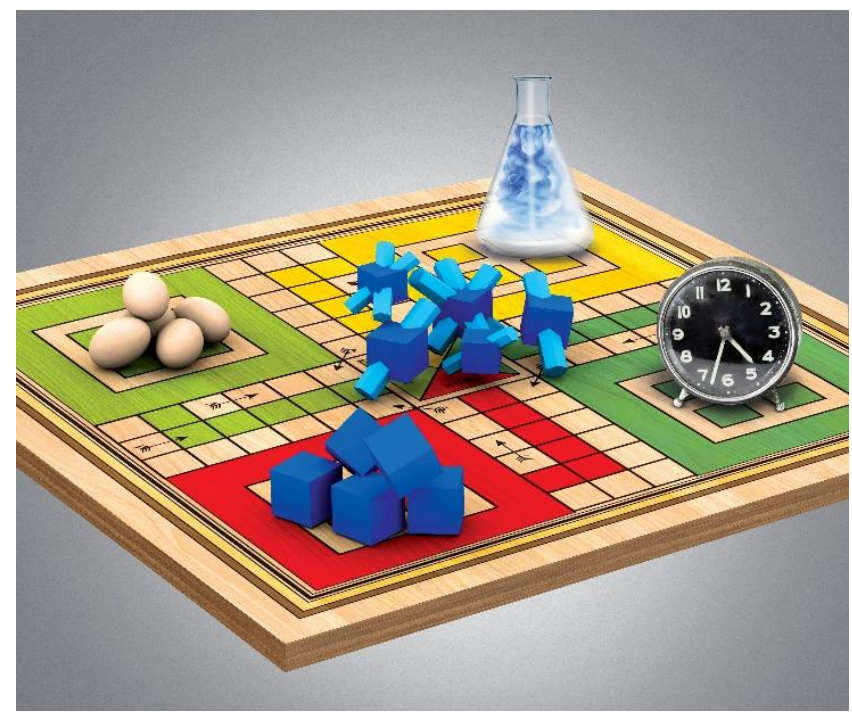

Graphical abstract 